\title{
02;07
}

\section{Образование кластеров спайков в CMOS-матрицах, облученных протонами и нейтронами}

\author{
(C) Н.А. Иванов ${ }^{1}$, О.В. Лобанов ${ }^{1}$, В.В. Пашук ${ }^{1}$, \\ М.О. Прыгунов ${ }^{2}$, К.Г. Сизова ${ }^{3, \uparrow}$ \\ ${ }^{1}$ Петербургский институт ядерной физики им. Б.П. Константинова \\ НИЦ „Курчатовский институт“, Гатчина, Ленинградская обл., Россия \\ 2 ООО „О2 Световые Системы“, Санкт-Петербург, Россия \\ ${ }^{3} \mathrm{OOO} \mathrm{„НПЦ} \mathrm{„Гранат“,} \mathrm{Санкт-Петербург,} \mathrm{Россия}$ \\ ฯE-mail: ksizova@npcgranat.ru
}

Поступило в Редакцию 9 июля 2018 г.

Исследованы распределения пикселей с большой величиной темнового тока в CMOS-матрицах, облученных протонами с энергией $1000 \mathrm{MeV}$ и нейтронами сплошного спектра, моделирующего энергетический спектр атмосферных нейтронов. Получены данные об образовании кластеров спайков в облученных матрицах и влиянии времени экспозиции на параметры кластеров.

DOI: 10.21883/PJTF.2018.21.46855.17457

В светочувствительных матрицах эффект воздействия отдельных частиц проявляется в возникновении спайков - поврежденных пикселей с величинами темновых токов $\left(I_{d c}\right)$, значительно превышающими средние значения темновых токов в пикселях исходной необлученной матрицы. При облучении протонами и нейтронами спайки преимущественно образуются в результате ядерных реакций, продукты которых создают структурные радиационные дефекты в чувствительной области пикселей [1]. В работах [2,3] было установлено, что под действием быстрых протонов и нейтронов в матрицах на основе приборов с зарядовой связью (CCD-матрицах) ICX259AL марки Sony c размером пикселей $6.50 \times 6.25 \mu \mathrm{m}$ возникают кластеры (скопления) спайков, которые включают несколько соседних поврежденных пикселей с большими величинами $I_{d c}$ и имеют линейные размеры до $\sim 20 \mu \mathrm{m}$.

В настоящей работе изучается образование спайков под действием протонов и нейтронов в матрицах на основе комплементарной 


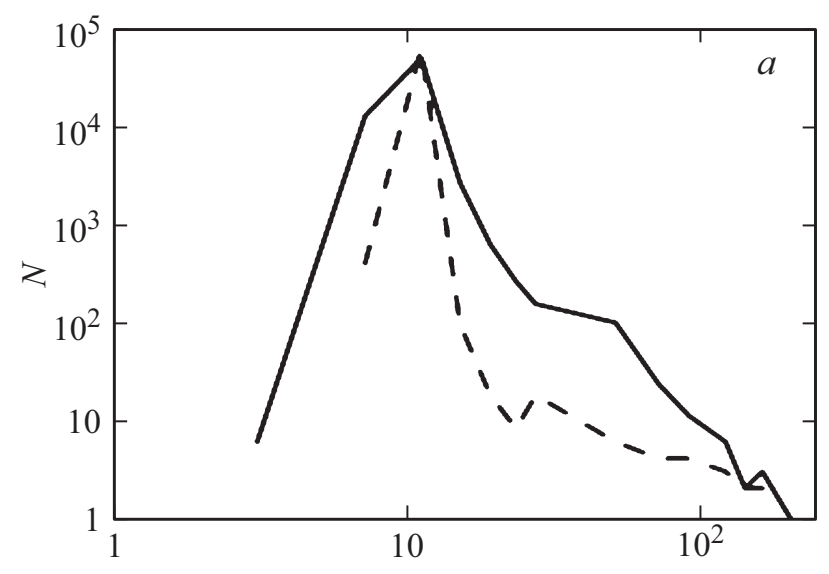

$I_{d c}$, rel. un.

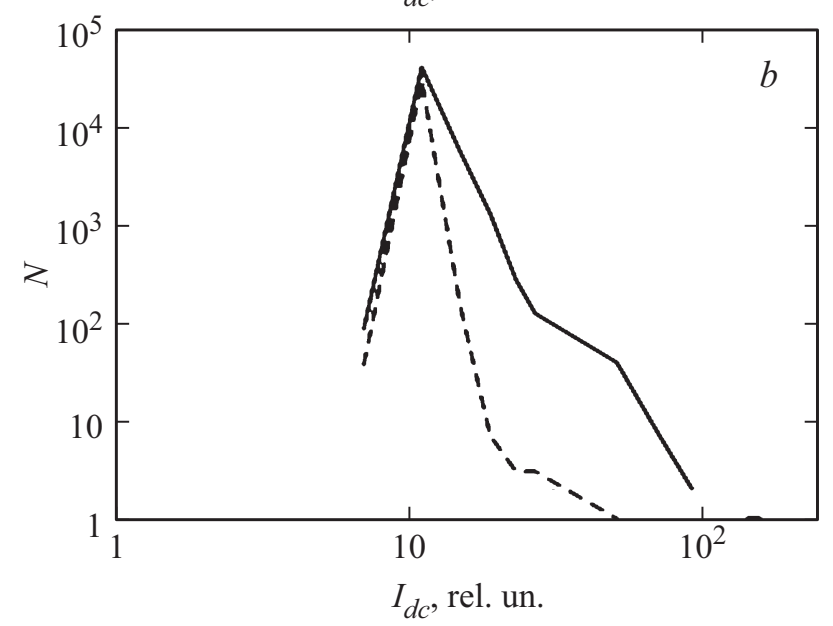

Рис. 1. Распределения величин темнового тока в пикселях CMOS-матриц, облученных протонами $(a)$ и нейтронами $(b)$. Время экспозиции $32 \mathrm{~ms}$ (сплошная линия) и $0.5 \mathrm{~ms}$ (штриховая линия).

структуры металл-оксид-полупроводник (CMOS-матрицы), которые благодаря своим техническим характеристикам и низкой стоимости в последнее десятилетие практически заменили CCD-матрицы в элект-

4 Письма в ЖТФ, 2018, том 44, вып. 21 

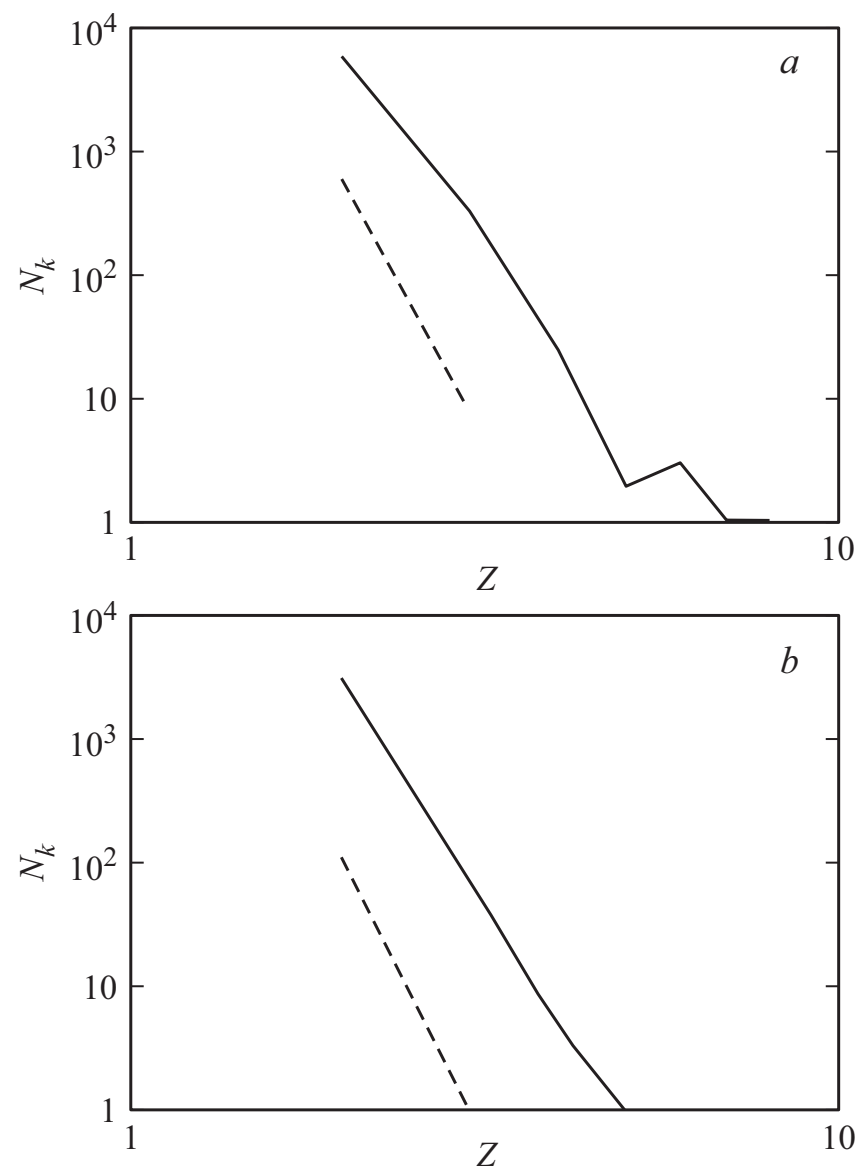

Рис. 2. Распределения количества кластеров по числу входящих в них спайков в матрицах, облученных протонами $(a)$ и нейтронами $(b)$. Время экспозиции $32 \mathrm{~ms}$ (сплошная линия) и $0.5 \mathrm{~ms}$ (штриховая линия).

ронной аппаратуре. Исследовались CMOS-матрицы MT9M034 производства фирмы ON Semiconductor с размером кристалла $4.8 \times 3.6 \mathrm{~mm}$, размером пикселя $3.75 \times 3.75 \mu \mathrm{m}$ и количеством активных пикселей $1280 \times 960$. Облучение проводилось протонами с энергией $1000 \mathrm{MeV}$

Письма в ЖТФ, 2018, том 44, вып. 21 

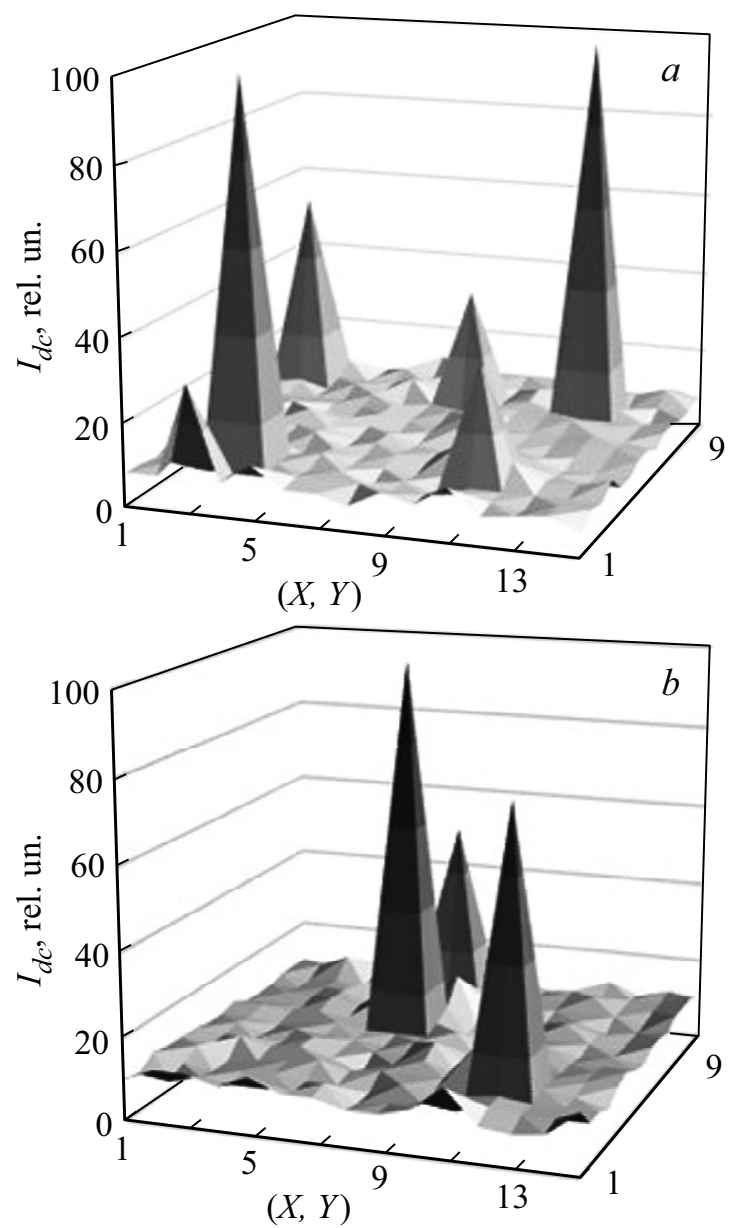

Рис. 3. Рельефы кластеров спайков в CMOS-матрице при облучении протонами до флюенса $10^{10} \mathrm{~cm}^{-2}(a)$ и нейтронами до флюенса $2.8 \cdot 10^{7} \mathrm{~cm}^{-2}(b)$ при временах экспозиции $32 \mathrm{~ms}$.

на синхроциклотроне С-1000 до флюенса $F_{p}=10^{10} \mathrm{~cm}^{-2}$ и нейтронами атмосферного спектра с максимальной энергией $1000 \mathrm{MeV}$ на установке ГНЕЙС [4] до флюенса $F_{n}=2.8 \cdot 10^{7} \mathrm{~cm}^{-2}$. Мето-

4* Письма в ЖТФ, 2018, том 44, вып. 21 
дика облучения протонами и нейтронами при флюенсах частиц $10^{7}-10^{10} \mathrm{~cm}^{-2}$ аналогична описанной в работах [2,3]. Величины $I_{d c}$ определялись по степени яркости пикселя матрицы в относительных единицах (rel. un.) целым числом в диапазоне от 0 (черное) до 255 (белое).

На рис. 1 приведены измеренные при температуре $25^{\circ} \mathrm{C}$ распределения пикселей по величине темнового тока в облученных протонами и нейтронами CMOS-матрицах при различных временах экспозиции (выдержки до момента измерения значения темнового тока). Поскольку в исходных матрицах величины темновых токов не превышали 20 rel. un., спайками мы считали пиксели, величина $I_{d c}$ в которых после облучения превышала 20 rel. un.

На рис. 2 показаны распределения количества кластеров $N_{k}$ по числу входящих в них спайков при различных временах экспозиции в CMOS-матрицах, облученных протонами и нейтронами. Размеры кластеров и величины темновых токов в спайках, входящих в их состав, в сильной степени зависят от времени экспозиции и практически не зависят от природы нуклонов. В качестве примера на рис. 3 приведены участки облученных протонами и нейтронами CMOS-матриц с типичными „рельефами“ кластеров спайков при времени экспозиции $32 \mathrm{~ms}$. Максимальный размер кластеров, приведенных на рис. 3, составляет $\sim 11.75 \times 11.75 \mu \mathrm{m}$ и включает в себя девять спайков.

К образованию кластеров способны приводить наиболее длиннопробежные частицы из числа продуктов ядерных реакций нуклонов с ядрами кремния. В таблице приведены величины пробегов различных ядер отдачи [5], образующихся с максимальными энергиями в ядерных реакциях протонов с энергией $1000 \mathrm{MeV}$ с ядрами атомов кремния [6] (продукты ядерных реакций нейтронов атмосферного спектра с максимальной энергией $1000 \mathrm{MeV}$ имеют аналогичный состав и величины пробегов). Из таблицы видно, что такие ядра отдачи, как неон, кислород и углерод, имеют пробеги, достаточные для создания кластеров спайков наблюдаемых размеров. Следует также иметь в виду, что эти ядра отдачи в процессе торможения проходят область максимальных значений линейных потерь энергии на ионизацию и испытывают упругие атоматомные соударения [5,6].

При флюенсе протонов $10^{10} \mathrm{~cm}^{-2}$ и времени экспозиции $32 \mathrm{~ms}$ количество событий $n$ от отдельных частиц составило 28926 , в том

Письма в ЖТФ, 2018, том 44, вып. 21 
Пробеги ядер отдачи, образующихся с максимальными энергиями в ядерных реакциях протонов с энергией $1000 \mathrm{MeV}$ с ядрами атомов кремния

\begin{tabular}{c|c|c|c|c}
\hline \multirow{2}{*}{ Параметр } & \multicolumn{4}{|c}{ Тип ядра отдачи } \\
\cline { 2 - 5 } & ${ }^{27} \mathrm{Al}$ & ${ }^{20} \mathrm{Ne}$ & ${ }^{16} \mathrm{O}$ & ${ }^{12} \mathrm{C}$ \\
\hline Энергия ядра отдачи, $\mathrm{MeV}$ & 7.5 & 24 & 46 & 53 \\
Пробег ядра, $\mu \mathrm{m}$ & 4.5 & 11 & 30 & 63
\end{tabular}

числе 20194 от кластеров и 8732 от спайков вне кластеров. Соответственно сечение возникновения событий от отдельных протонов в CMOS-матрице $\sum_{s p}$, равное $\sum_{s p}=n / F_{p}$, составило $2.9 \cdot 10^{-6} \mathrm{~cm}^{2}$, что качественно согласуется с величиной сечения ядерных реакций в объеме CMOS-матрицы $\left(\sum_{n r}\right)$

$$
\sum_{n r}=\sigma n_{\mathrm{Si}} V_{\mathrm{CMOS}} \approx 2.2 \cdot 10^{-6} \mathrm{~cm}^{2},
$$

где $\sigma=5 \cdot 10^{-25} \mathrm{~cm}^{2}-$ сечение ядерных реакций нуклонов с энергией $1000 \mathrm{MeV}$ с ядрами атомов кремния [7], $n_{\mathrm{Si}}=5.19 \cdot 10^{22} \mathrm{~cm}^{-3}-$ плотность атомов кремния, $V_{\mathrm{CMOS}}-$ объем CMOS-матрицы, принятый нами равным $0.86 \cdot 10^{-4} \mathrm{~cm}^{3}$ при толщине чувствительной области матрицы $5 \mu \mathrm{m}$.

Проведенные исследования показали следующее.

1. Механизм образования кластеров спайков в CMOS-матрицах MT9M034 и CCD-матрицах ICX259AL, облученных быстрыми протонами и нейтронами, аналогичен и обусловлен длиннопробежными остаточными ядрами, возникающими в результате ядерных реакций протонов и нейтронов с ядрами кремния.

2. Размеры кластеров и величины темновых токов в спайках, входящих в их состав, в сильной степени зависят от времени экспозиции и практически не зависят от природы нуклонов.

3. Возникновение кластеров спайков под действием протонов и нейтронов указывает на возможность множественных сбоев и отказов в интегральных схемах с размером чувствительных областей, близким и меньшим размера пикселей в CMOS-матрицах.

Письма в ЖТФ, 2018, том 44, вып. 21 


\section{Список литературы}

[1] Hopkinson G.R., Goiffon V., Mohammadzadeh A. // IEEE Trans. Nucl. Sci. 2008. V. 55. N 4. P. $2197-2204$.

[2] Ермаков К.Н., Иванов Н.А., Лобанов О.В., Пашук В.В., Тверской М.Г., Любинский С.М. // Письма в ЖТФ. 2010. Т. 36. В. 13. С. 54-60.

[3] Иванов Н.А., Лобанов О.В., Митин Е.В., Пашук В.В., Тверской М.Г. // Письма в ЖТФ. 2013. Т. 39. В. 17. С. 35-43.

[4] Абросимов Н.К., Вайшнене Л.А., Воробьев А.С., Иванов Е.М., Михеев Г.Ф., Рябов Г.А., Тверской М.Г., Щербаков О.А. // Приборы и техника эксперимента. 2010. № 4. С. 5-12.

[5] Физические величины. Справочник / Под ред. И.С. Григорьева, Е.3. Мейлихова. М.: Энергоатомиздат, 1991. 1232 с.

[6] Ермаков К.Н., Иванов Н.А., Пашук В.В., Тверской М.Г. // Вопр. атомной науки и техники. Сер. Физика радиационного воздействия на радиоэлектронную аппаратуру. Науч.-техн. сб. М., 2007. В. 1-2. С. 20-23.

[7] Барашенков В.С. Сечения взаимодействия частиц и ядер с ядрами. Дубна: ОИЯИ, 1993, $346 \mathrm{c.}$ 